\title{
Educational inequalities in the midst of persistent poverty: Diversity across Africa in educational outcomes
}

Cynthia B. Lloyd

Population Council

Paul C. Hewett

Population Council

Follow this and additional works at: https://knowledgecommons.popcouncil.org/departments_sbsr-pgy

Part of the Demography, Population, and Ecology Commons, Family, Life Course, and Society

Commons, Gender and Sexuality Commons, Gender Equity in Education Commons, and the International

Public Health Commons

How does access to this work benefit you? Let us know!

\section{Recommended Citation}

Lloyd, Cynthia B. and Paul C. Hewett. 2009. "Educational inequalities in the midst of persistent poverty: Diversity across Africa in educational outcomes," Poverty, Gender, and Youth Working Paper no. 14. New York: Population Council. Version of record: https://doi.org/10.1002/jid.1650 


\section{POVERTY, GENDER, AND YOUTH}

\section{Educational Inequalities in the}

Midst of Persistent Poverty:

Diversity across Africa in Educational Outcomes

Cynthia B. Lloyd and Paul C. Hewett 


\section{(2) Population Council}

One Dag Hammarskjold Plaza

New York, New York 10017 USA

www.popcouncil.org

pubinfo@popcouncil.org

For information on Poverty, Gender, and Youth working papers, see www.popcouncil.org/publications/wp/index.html

This material may not be reproduced without written permission from the authors.

ISSN: $1554-8538$

(C) 2009 The Population Council, Inc. 


\title{
Educational Inequalities in the Midst of Persistent Poverty: Diversity across Africa in Educational Outcomes
}

\author{
Cynthia B. Lloyd \\ Paul C. Hewett
}

Cynthia B. Lloyd is Senior Associate and Paul C. Hewett is Associate, Population Council, New York.

The authors acknowledge support from the William and Flora Hewlett Foundation. A previous version of this paper was presented at a conference on "Mapping Global Inequalities" at the University of California, Santa Cruz on December 13, 2007. 


\begin{abstract}
This paper explores inequalities in education across sub-Saharan Africa. Although we mainly focus on primary school completion rates, attention is also given to literacy as a more proximate indicator of human capital acquisition. Using data from the Demographic and Health Surveys and UNICEF's Multiple Indicator Cluster Surveys, we explore cross-country variations in primary school completion rates, gender and wealth gaps in education, and literacy rates in relation to one another and in relation to cross-country variations in national income per capita. While these data paint a picture of overall educational progress, particularly for girls, this general picture is juxtaposed against an extremely diverse landscape across Africa with respect to primary school completion rates and retained literacy. Although cross-country variation in primary school completion rates can be partially explained by variation in national per capita income, the same cannot be said for literacy rates. Even the poorest countries have significant variation in achieved literacy, suggesting that learning can occur even in resource-poor environments. At the same time, our findings are sobering: in many countries, international educational goals are unlikely to be reached by 2015, and poor learning outcomes are frequently widespread.
\end{abstract}


Rapid globalization has drawn increased attention to the widening of inequalities both within and between countries. As the elite in the poorest countries find opportunities in the global economy, often thanks to their access to superior educational opportunities, the gulf between rich and poor has been widening. Some countries appear better positioned than others to capture and build upon natural and human resources, as well as social and economic investments. There is striking diversity within and across the poorest countries in the extent and effectiveness of human capital investments and their distribution across sub-populations. Gender gaps vary widely, as do gaps between rich and poor, between rural and urban areas, and between the majority population and minority or other excluded groups.

Our focus here is on education as a source and reflection of social and economic inequality, both because of its recognized value as a key component of human development and because of its contribution to individual earnings and national economic development. The UNDP's annual Human Development Report, which charts national progress in human capital, is built on an intellectual framework developed by Amartya Sen and Mahbub ul Haq, among others. They recognized that human development encompasses more than the growth of incomes and extends to the development of human capabilities (UNDP 1990). Knowledge acquisition is a key component of human capital. With the spread of mass education, knowledge acquisition is often associated with formal schooling.

This paper explores inequalities in education across sub-Saharan Africa, the poorest continent. We focus mainly on primary school completion rates, given that universal primary school completion by 2015 is one of the UN Millennium Development Goals, but we also look at literacy as a more proximate indicator of human capital acquisition. Using data from the Demographic and Health Surveys (DHS) and UNICEF's Multiple Indicator Cluster Surveys (MICS), we first explore general trends in primary school completion across Africa and then assess differential progress among boys and girls over the last 30 years or so. We also examine cross-country variations in primary school completion rates, gender gaps, and literacy in relation to cross-country variations in national income per capita. The DHS and MICS data allow us to examine withincountry inequalities in primary school completion by household wealth.

While these data paint a picture of overall educational progress, particularly for girls, this general picture is juxtaposed against an extremely diverse landscape across Africa with respect to primary school completion rates and retained literacy. Although cross-country variation in primary school completion rates can be partially explained by variation in national per capita income, the same cannot be said for literacy rates-a measure that more closely captures learning outcomes. Even among the poorest countries, there is significant variation in achieved literacy, suggesting that learning can occur even in resource-poor environments. At the same time, our findings are sobering: in many African countries, international educational goals are unlikely to be reached by 2015, and poor learning outcomes are frequently widespread. 


\section{Trends in Primary School Completion in Sub-Saharan Africa}

Sub-Saharan Africa has the lowest primary school completion rates of any world region (Bruns et al. 2003). It is also estimated to have the highest rates of poverty (Chen and Ravallion 2008). To examine trends in primary school completion rates, we use nationally representative household data on educational participation and attainment from the Demographic and Health Surveys and the Multiple Indicator Cluster Surveys, together covering 33 countries and 88 percent of the sub-Saharan African population. These data are largely comparable across countries, with survey dates ranging from 1998 to 2007 (see Appendix Table 1).

Trends in schooling can be derived from a single household survey by comparing schooling participation and attainment across age cohorts (Hewett and Lloyd 2005). Differences between older and younger cohorts can be interpreted as trends as long as the youngest cohort has reached a sufficient age to allow for all members of that cohort to have achieved the level of schooling measured. ${ }^{1}$ One advantage of these data relative to data collected by UNESCO on trends in gross and net enrollment rates is that the numerators and denominators of estimated rates are derived from the same data source and can be calculated specific to the same age cohort.

Figure 1 summarizes, for the region as a whole, trends in the percent of girls and boys completing primary school over the past 30 years. Because the median date for these surveys is 2003, we can assume that these data provide a snapshot of primary school completion up through the beginning of the 21 st century. The estimated trends are averages weighted by the population aged 10-24 in 2005 for each country (United Nations 2007). The size of the youth population represented by the data varies enormously, from a quarter of a million in Comoros to over 47 million in Nigeria (see Appendix Table 1). We have projected the rates of primary school completion for the youngest groups aged 10-14 and 15-19 on the basis of relationships observed between past trends in three indicators: ever attended, grade 4 completion, and primary school completion. Trends for these indicators track very closely together by age, providing confidence in our projections of primary school completion rates up through the first few years of this century. ${ }^{2}$

In the first years of the 21 st century, we estimate that 60 percent of boys aged 10 14 in sub-Saharan Africa had completed primary school. Over the previous 30 years, primary school completion rates for boys have risen quite slowly, beginning at 48 percent, with negligible growth in the last 15 years. By contrast, over the same three decades, girls' primary school completion rates have risen steadily, almost doubling from 30 percent to 56 percent. These estimates indicate that the gender gap in sub-Saharan Africa, which was very wide in the early years of independence, has narrowed steadily and consistently, largely owing to steady gains in educational achievement for girls.

The most recent estimates suggest a gender gap of only 4 percentage points in favor of boys. If current trends continue, it is very likely that the gender gap in the region will be eliminated soon, although at levels substantially below the Millennium Development Goal of universal primary school completion. This conclusion does not 
imply that the gender gap will be eliminated in every country, rather that girls will have gained a sufficient relative advantage in some countries to balance their relative disadvantage in others. In fact, the regional averages presented above disguise substantial diversity in primary school completion rates within the region, as some of the most populous countries (see Appendix Table 1: Kenya, Nigeria, South Africa, and Tanzania) also have some of the highest completion rates and smallest gender gaps.

\section{Cross-country inequalities in primary school completion by gender}

Figure 2 presents trends over 20 years in the percent of boys and girls completing primary school, with countries ranked from high to low (left to right) according to completion rates for girls. Values at the top of the bars indicate percentage point changes in primary school completion between the younger (20-24) and older (40-44) cohorts. For each country, girls' rates are positioned directly above boys' rates to facilitate comparison. This figure illustrates the large diversity in educational performance over time across the continent, with respect both to overall levels and to gender differences. Current primary school completion rates vary from a dismally low 8 percent for girls and 19 percent for boys in Niger to a high of 90 percent for girls and 86 percent for boys in South Africa. In the case of girls, eight countries have seen gains of 20 percentage points or more during these two decades. Progress has by and large been greater in those countries that had already attained higher completion rates 20 years ago (South Africa, Namibia, Swaziland, and Zimbabwe). The other two countries with substantial gains, Nigeria and Comoros, have had strong performance despite lower initial levels of girls' primary school completion.

For boys, Figure 2 indicates that absolute growth in the percent completing primary school has not been as strong or consistent as for girls. Indeed some countries have even recorded a decline. In only ten of 33 countries are boys' absolute gains equal to or greater than those of girls, and in only two of these (Guinea and Chad) are the differences large. In six countries primary school completion rates for boys have declined over time, significantly so in the case of Congo-Brazzaville ( -12 percent), Tanzania $(-8$ percent), and Zambia ( -10 percent); in no country is a decline in the percent completing primary school observed for girls.

A question that arises is how cross-country variations in primary school completion might be associated with cross-country variations in per capita national income. Excluding Gabon because its per capita income is an outlier within the region, Figure 3 presents primary school completion rates by gross national income per capita adjusted for purchasing power parity, including both the data points for each country and a predicted regression line. The PPP GNI for each country is averaged across the five years during which members of the 20-24 cohort would have been aged 10 (see Appendix Table 1). The average represents a proxy for the general economic circumstances of the country when each child attended primary school. Although a crude measure, the average PPP GNI at age 10 should represent the opportunity structure for children at the beginning of their primary school years. 
With the expectation that the most plausible relationship between primary school completion and GNI is curvilinear, we generated a least squares non-linear regression line that best fit the data. Our non-linear regression explains respectively 53 percent and 33 percent of variance in girls' and boys' primary school completion (see Figure 3 ). The estimated regression line implies that advances in primary school completion rates are greatest at lower levels of per capita GNI, with gains in education diminishing at higher levels of income. For example, when per capita income is only $\$ 500$, an increase of $\$ 100$ per capita is associated with a 4 percentage point increase in the percent of girls completing primary school. To achieve similar growth in primary school completion for girls at higher per capita incomes, twice as much income growth (\$200 per capita) is required for countries with a GNI of $\$ 2000$, while ten times as much growth in income ( $\$ 1000$ per capita) is required for countries with per capita GNI of $\$ 4000$. Figure 3 indicates, too, that girls benefit more from changes in per capita income than do boys, albeit starting at significantly lower levels of primary school completion.

Figure 3 also illustrates the wide diversity in experience across countries. For instance, some of the very poorest countries have achieved impressive levels of schooling despite their poverty, with Kenya, Nigeria, Ghana, and Tanzania exemplifying poor countries with greater than average primary school completion rates. Among the 24 poorest countries with PPP GNI per capita of $\$ 1000$ or less, the variation in primary school completion for girls ranges from 8 percent in Niger to 67 percent in Ghana. Among the relatively few countries with PPP GNI per capital ranging from $\$ 1000$ to $\$ 2000$, the variation in completion rates across Africa is still large, ranging from 35 percent in Côte d'Ivoire to 76 percent in Lesotho.

As illustrated in Figure 4, in all but six countries-Kenya, South Africa, Namibia, Swaziland, Lesotho, and Madagascar-girls aged 20-24 remained at a disadvantage as measured by the absolute percentage point gender gap in primary school completion rates. Gender gaps to the disadvantage of girls of 10 percentage points or less-roughly the regional average - can be found in Cameroon, Congo (Brazzaville), Gabon, Rwanda, Tanzania, and Zimbabwe. At the other extreme, gender gaps of 20 percentage points or more still exist in Benin, Central African Republic, Chad, Democratic Republic of Congo, Gambia, Guinea, and Togo; and among these countries the gap has increased substantially in Guinea and Chad owing to recent increases in primary school completion rates for boys. Gender gaps for the other 14 countries were in the 10 to 19 percentage point range.

In Figure 5, we explore cross-country variation in the gender gap by PPP GNI per capita using the same approach as above. In this case, approximately 28 percent of the variance in the gender gap is explained by GNI per capita. We see a tendency for the gender gap to narrow and start to favor girls at higher levels of national income, although at a slower pace as per capita income grows. As with primary school completion rates, there is a wide diversity in experience among the poorest countries, with some (Kenya, Madagascar, Tanzania, and Rwanda) achieving near gender parity in primary school completion at relatively low incomes. Furthermore, the size of the gender gap does not appear to be associated with levels of primary school completion for boys. We see small 
gender gaps in countries where boys' primary school completion rates are relatively high such as Zimbabwe, South Africa, and Tanzania but also in countries where boys' primary school completion rates are extremely low such as Rwanda and Madagascar.

\section{Cross-country inequalities in literacy for young women}

The international thrust toward universal primary school completion by 2015, as laid out both in the Millennium Development Goals and in the Education for All Goals adopted at the World Education Forum in Dakar in 2000, is predicated on the assumption that primary school completion confers a basic education including functional literacy and numeracy. However, accumulating evidence suggests that, while literacy improves with schooling, the correlation between the two is far from perfect, largely because of variations in school quality (Lloyd 2009). Until recently, international indicators of literacy, usually derived from national censuses or surveys, were based on self-reports. These literacy data are now widely acknowledged by UNESCO and other UN agencies to be seriously flawed (NRC/IOM 2005). In response, recent DHS surveys have added an objective assessment of literacy by asking women of reproductive age to read a complete

sentence out loud as part of the interview. ${ }^{3}$ Only women with less than a secondary school education were asked to participate in this part of the questionnaire, on the assumption that women who have attended secondary school would have reached at least this basic level of literacy. These data are available for 24 of the 33 countries assessed here. Figure 6 presents literacy rates at grade 5 by primary school completion rates for young women aged 20-24. We chose grade 5 because it is the penultimate year of primary school in most countries, and we would expect that in a well-functioning school all students should at a minimum have acquired basic literacy by grade 5 . With a correlation of no more than 1 percent, it is clear that primary school completion rates cannot be assumed to capture cross-national differences in learning.

When we compare cross-country differences in retained literacy at grade 5 for women aged 20-24 according to PPP GNI per capita, countries with similar levels of income have achieved widely varying basic learning outcomes in primary school (Figure 7). Indeed with an adjusted R-square of near zero, there appears to be very little association between GNI per capita and basic learning outcomes. This stands in contrast to the relationships between primary school completion and GNI per capita explored above. For instance, at the low end of national income per capita, less than 10 percent of young women in Ghana could read a simple sentence by grade 5 while well over 90 percent could do so in Rwanda. At higher levels of income, Namibia does much better (61 percent of women could read a sentence) than either Congo-Brazzaville (15 percent) or Zimbabwe (24 percent). Of course, the greatest variance is among the poorer countries, where widely varying learning outcomes in primary school are mostly likely due to crosscountry differences in school quality. 


\section{Within-country wealth inequalities in primary school completion}

While UNESCO data do not allow us to explore differential primary school completion rates by subgroups of interest, the DHS data provide an opportunity to illustrate differentials in educational achievement by subcategories, including urban/rural, ethnicity, religion, and language group. Here we focus solely on the relationship between completion rates and household wealth status. ${ }^{4}$ Although direct measures of household income and consumption are not available in the DHS or MICS-2, proxy measures of living standards can be generated at the household level using alternative indicators. ${ }^{5}$

The measure used here is based on an asset index generated from a set of household durables, including the ownership of a radio, refrigerator, bicycle, motorcycle, or car, as well as various indicators of housing quality, including whether the household has finished floors and the number of rooms that are used for sleeping. ${ }^{6}$ Similar to the procedure used by Filmer and Pritchett (1999, 2001), we define the "poorest" as those residing in households in the bottom two quintiles (or 40 percent) of the asset index and the "best-off" as those residing in households in the top quintile (or 20 percent). ${ }^{7}$

Figures $8 \mathrm{a}$ and $\mathrm{b}$ contrast the levels of primary school completion achieved by members of the poorest and the best-off households for the age group 20-24 for boys and girls separately. Countries are ordered from low to high according to the completion rates of girls residing in the best-off households. Even among the best-off households, completion rates vary enormously from about 25 percent to over 95 percent for girls and from 40 percent to over 95 percent for boys. In no country has universal primary schooling been achieved by the poorest households. South Africa come closest with over 80 percent of the poorest girls completing primary school. Only in Swaziland, Congo (Brazzaville), Tanzania, Gabon, Namibia, Zimbabwe, Democratic Republic of Congo, South Africa, Ghana, and Nigeria do completion rates for poor boys exceed 50 percent. The poorest girls in the same set of countries have completion rates ranging from 25 to 80 percent. In most other countries, completion rates for the poorest girls fall below 30 percent. Furthermore, the poor are likely to attend schools of much lower quality than the better-off, suggesting that the educational differentials presented here substantially underestimate the real differentials in learning outcomes.

As a next step, we developed an index of educational inequality by household wealth, in order to compare the extent of the poverty disadvantage for boys and girls separately. The inequality index is calculated as one minus the ratio of the percent completing primary school from the poorest 40 percent of households, relative to the best-off 20 percent of households. This measure of educational inequality ranges from zero to one, with zero representing complete parity of attainment between the best-off 20 percent and the poorest 40 percent in a given country, and one indicating a complete lack of parity in educational attainment by the poor. A measure of 0.5 implies that the poor have reached 50 percent of the levels of educational attainment of the best-off. ${ }^{8}$

Table 1 presents the inequality index for primary school completion by wealth status for boys and girls separately as well as the gender gap in the inequality index. The 33 countries listed are ordered from high to low inequality using the index for girls. 
Indexes exceed 0.50 in 18 of the countries for boys and 22 countries for girls, attesting to the wide differentials in primary school completion by household economic status. In all but six countries, the index of inequality is substantially higher for girls than boys, supporting the widely held belief that gender inequalities in primary school completion are magnified among the poor, with potentially even more serious consequences for girls in terms of access to schools of reasonable quality. Differences of more than 10 percentage points in the index between boys and girls can be found in 21 of the 33 countries. Inequalities for boys are greater than those for girls in Lesotho, Kenya, Namibia, South Africa, Swaziland, and Côte d'Ivoire. In Lesotho, in particular, there is significantly greater inequality among boys than girls. This is due to differentials in primary school completion, with poor girls in Lesotho attaining 31 percent higher completion rates than poor boys, an unusual pattern for sub-Saharan Africa.

The results in Table 1 strongly support the case for developing indicators to monitor educational progress that can be differentiated by wealth status. The results also suggest that further efforts to close the gender gap should focus particularly on the poorest households, whose lack of access to and/or lack of success in primary school seems to exceed what might be expected on the basis of differences in household wealth alone, suggesting consideration of additional factors such as discrimination and corruption that together can limit the horizons of the disadvantaged.

\section{Why are some poor countries doing much better than others?}

Young men and women aged 20-24 when surveyed at the beginning of the 21st century would have entered school in Africa during the latter half of the 1980s, before many recent school reforms and universal primary schooling policies. Those aged 40-44 would have entered school in the early 1970s when many of these countries were just emerging from colonial rule. Thus, some of the determinants of the observed crosscountry and within-country inequalities by gender and wealth lie in the past and could include a range of social, political, institutional, and economic factors.

One of the most important determinants of a child's schooling level is the schooling of his/her parents (see NRC/IOM 2005 for a review of the literature). Figure 9, which is restricted to countries with a PPP GNI less than $\$ 1000$ in order to focus on outcomes among the poorest countries, shows a strong positive correlation for both boys and girls between the primary school completion rates of those aged 40-44 and those aged 20-24. The differential investments in education by former colonial rulers continue to exert an impact on the cross-country inequalities observed among young people today. As Figure 9 indicates, countries with an Anglophone tradition achieved higher grade levels than countries with other colonial traditions. While the British were committed to providing a basic education for the general population, other colonial powers, including France, Portugal, and Belgium, invested solely in the education of a small elite needed to serve their administrative needs (Lloyd, Kaufman, and Hewett 2000). Thus, the countries with a former French colonial heritage tend to be concentrated toward the lower left hand corner of the chart, indicating relatively low educational attainment both 20 years ago and 
more recently. By contrast, the countries with a former British heritage mostly tend to be further to the upper right, indicating higher levels of primary school completion.

While these patterns might suggest that history is destiny, a look at the literacy data for a selection of the poorest African countries provides a potentially surprising counterpoint. Figure 10 indicates the percent of young women able to read a simple sentence by grade attained, among those who did not go on to secondary school. The countries, selected to capture the full range of literacy rates observed within this group of the 24 poorest countries, include countries from all colonial traditions. Levels of literacy vary sharply, ranging from a high of 95 percent in Rwanda at grade 5 to a low of 20 percent in Mali. Two countries with a British colonial tradition-Malawi and Zambiaranked among the highest and lowest on literacy respectively, even though Zambia is estimated to have achieved a primary school completion rate that is more than 20 percentage points higher than Malawi's (former colonial affiliations are included and primary school completion rates appear for each country in parentheses in Figure 10). For those countries with data on both literacy and primary school completion for young women aged 20-24, the correlation between these two indicators is surprisingly low at .01 , suggesting that current cross-country comparisons that neglect educational outcomes and focus only on enrollment and grade attainment may be missing an important part of the story.

\section{CONCLUSIONS AND IMPLICATIONS}

We have shown that primary school completion rates in most countries of subSaharan Africa remain far below levels required to achieve the Millennium Development Goal of universal primary school completion by 2015. Although girls' rates of primary school completion have increased in the past few decades, African boys have not seen meaningful progress in attainment for over 15 years. If increased enrollment and the movement toward universal access to primary education are to have an impact on the attainment of a basic level of education and the acquisition of fundamental competencies, a greater understanding of educational trends, patterns, and policies in Africa is a necessary starting point.

We have found surprising differences across Africa not only in overall primary school completion rates but also in within-country inequalities by gender and household wealth, even in the poorest countries. For example, among the 24 countries with per capita gross national incomes below $\$ 1000$, primary school completion rates for girls aged 20-24 range from a high of 67 percent in Ghana to a low of 8 percent in Niger. An even wider variation in literacy rates is seen among young women across countries with similar national incomes, from around 20 percent in Mali to over 90 percent in Rwanda. Gender gaps and wealth inequalities in primary school completion rates vary widely among this group of countries as well. For example, gender gaps in primary school completion vary from a high of 36 percentage points in Guinea to near equality in Kenya, Madagascar, Tanzania, and Rwanda, despite significant variation among these latter four 
countries in overall levels of primary school completion for girls (ranging from 25 to 65 percent). Cross-country inequalities provide only a weak and partial explanation for observed cross-country inequalities in literacy rates, which are a better indicator of learning than primary school completion rates. Some very poor countries have done remarkably well; some relatively rich countries within the continent have done poorly.

While most African countries have seen notable improvements in the percent completing primary school over the past 20 years, particularly for girls, the countries with the lowest completion rates today are by and large the same countries whose completion rates were among the lowest 20 years ago. Among the countries achieving higher percentages completing primary school soon after independence, there is a range of trends over the past 20 years, with some countries having achieved more impressive gains than others. Cross-country differences in the percent completing primary school and in learning outcomes, gender gaps, and relative wealth gaps within Africa are not fully explained by cross-country differences in national income per capita. As we observed, some very poor countries have achieved relatively high primary school completion and/or low gender gaps despite relatively low levels of economic development as conventionally measured. This achievement is also reflected, for some countries, in higher levels of literacy.

While the roots of these differences lie in the past, with differential investments made by former colonial rulers, it is clear from these data that other factors are important as well. External resources will continue to make a difference in a continent that remains extremely poor while experiencing very rapid population growth rates, particularly in the school-going ages. The effects of recent school reforms, including the waiving of primary school fees, will only be seen in primary school completion rates achieved at the end of this decade. Given the demonstrated connection between school quality and grade attainment, we predict that those countries that have been able to maintain school quality in the face of a massive rise in enrollment, often with substantial help from the donor community, will be much more likely than others to achieve universal primary school completion.

\section{NOTES}

1 Differences in mortality by education can bias estimates of trends. It is typically expected that the better-educated have lower mortality rates. Thus, we would assume that estimates of primary school completion rates among older cohorts will be biased upward because of the lower mortality of the better-educated, while estimates of current cohorts will be measured more accurately. As a result, rates of educational progress relative to the past will be underestimated. In the context of AIDS, however, educational differentials in mortality may have shifted in Africa. We are unaware of recent estimates of mortality by education and therefore cannot assess the extent of the potential bias or how it might be changing. For full discussion, see Hewett and Lloyd (2005). 
2 See Hewett and Lloyd (2005) for data on trends in ever attendance and grade four completion and for a full explanation of our estimation technique.

3 The interviewer has several simple sentences printed on cards that are chosen at random for each interview (in the language spoken locally). The four sentences used in the Uganda survey are as follows: (1) "Breast milk is good for babies," (2) "Most Ugandans live in a village," (3) "Immunization can prevent children from getting diseases," (4) "Family planning teaches people to be responsible for their family." UNESCO literacy data are based on self-reported ability to read.

The household survey provides a nationally representative sample of each age group. With advancing age, however, there is an increasing likelihood that an individual's household of residence is no longer his or her natal household. Thus, by linking a household wealth indicator with the percent completing primary school, we are assuming that, for those who no longer live in their natal home, there is a strong correlation between the relative wealth status of the parental home and the relative wealth status of the current household of residence. Given that household wealth categories divide the population into only three broad groups, this assumption is likely to be reasonable. Because of this concern, however, we do not examine wealth differentials for those over the ages of 20-24.

5 There has been substantial debate about how proxy measures of living standards can be generated from the variables typically available in household surveys (see for instance, Filmer and Pritchett 1999, 2001; Montgomery, Gragnolati, Burke, and Paredes 2000; Sahn and Stifel 2000; Bollen, Glanville, and Stecklov 2002).

6 For the smaller number of MICS-2 countries, we used the living standards index included in the data files. This measure employs an additional set of indicators, including access to electricity, sanitation, and piped drinking water, and is based on the Filmer and Pritchett wealth index calculation. Although constructed with slightly different components, the two indexes are highly correlated.

7 In addition to selecting the items that constitute the measures of living standards, another concern with generating a proxy measure of household living standards is how best to combine multiple items to create a single index. Sahn and Stifel (2000) chose the statistical tool of confirmatory factor analysis to develop their indicator of living standards and argued that such methods-relative to the principal components approach used by Filmer and Pritchett (1999) — are better grounded statistically and theoretically. In practice, however, few empirical differences have been found between these alternative approaches to generating a living standards index (Hewett and Montgomery 2001). Thus, we use the principal components technique, which is more commonly implemented and computationally simpler. When generating our measure of living standards, we 
included urban and rural areas together. In doing so, we may not capture all the subtleties of urban/rural wealth differences attributable to different consumption patterns and prices. For the purposes of this paper, however, such an approach allows us to explore, on a country-wide basis, the association between wealth and primary school completion.

8 Two countries with similar absolute gaps between household wealth groups can have different ratios because the ratio is constructed relative to the attendance rate of the more advantaged group. In countries where the most advantaged group has reached high levels of attendance, the variation in the ratio from zero to one represents a much wider range of performance for the less advantaged group than in countries where the most advantaged group is also performing poorly. 


\section{REFERENCES}

Bollen KA, Glanville JL, Stecklov G. 2002. Economic status proxies in studies of fertility in developing countries: Does the measure matter? Population Studies. 56: 81-96.

Bruns B, Mingat A, Rakotomalala R. 2003. Achieving Universal Primary Education by 2015: A Chance for Every Child. World Bank, Washington DC.

Chen S, Ravallion M. 2008. The developing world is poorer than we thought but no less successful in the fight against poverty. Policy Research Working Paper \#4703. World Bank: Washington DC.

Filmer D, Pritchett LH. 1999. The effect of household wealth on educational attainment: Evidence from 35 countries. Population and Development Review. 25 (1): 85-120.

Filmer D, Pritchett LH. 2001. Estimating wealth effects without expenditure data-or tears: An application to educational enrollments in states of India. Demography. 38 (1): 115-132.

Hewett PC, Lloyd CB 2005. Progress towards "Education for All": Trends and current challenges for sub-Saharan Africa. In The Changing Transitions to Adulthood in Developing Countries: Selected Studies, Lloyd CB, Cohen B, Behrman JR, Stromquist N. (eds). National Academies Press: Washington DC; 84-117.

Hewett PC, Montgomery MR. 2001. Poverty and public services in developing-country cities. Policy Research Division Working Paper No. 154. Population Council: New York.

Lloyd CB. 2009. The role of schools in promoting sexual and reproductive health among adolescents in developing countries. In Social Determinants of Sexual and Reproductive Health: Informing Future Research and Programme Needs, S. Malarcher (ed.). World Health Organization: Geneva. Forthcoming.

Lloyd CB, Kaufman CE, Hewett PC. 2000. The spread of primary schooling in subSaharan Africa: Implications for fertility change. Population and Development Review. 26 (3): 483-515.

Montgomery MR, Gragnolati M, Burke KA, Paredes E. 2000. Measuring living standards with proxy variables. Demography 37 (2): 155-174.

NRC/IOM (National Research Council and Institute of Medicine). 2005. Growing Up Global: The Changing Transitions to Adulthood in Developing Countries. Panel on Transitions to Adulthood in Developing Countries, Lloyd CB (ed.). National Academies Press, Washington DC. 
Sahn DE, Stifel DC. 2000. Poverty comparisons over time and across countries in Africa. World Development. 28(12): 2123-55.

UNDP 1990 Human Development Report 1990. Oxford University Press, New York.

United Nations. 2007. World Population Prospects: The 2006 Revision. United Nations, New York.

World Bank. 2006. World Development Indicators, 2006. Washington, DC: World Bank. World Bank. 2008. World Development Indicators, 2008. Washington, DC: World Bank. 
Table 1. Index of inequality in primary school completion for 20-24-year-olds, by household wealth

\begin{tabular}{|c|c|c|c|}
\hline Country & Boys & Girls & Gender gap \\
\hline Chad & 0.67 & 0.96 & -0.29 \\
\hline Mozambique & 0.78 & 0.95 & -0.17 \\
\hline Niger & 0.78 & 0.95 & -0.16 \\
\hline Mali & 0.90 & 0.94 & -0.04 \\
\hline Guinea Bissau & 0.79 & 0.94 & -0.15 \\
\hline Burkina Faso & 0.85 & 0.94 & -0.08 \\
\hline Benin & 0.76 & 0.93 & -0.17 \\
\hline Guinea & 0.68 & 0.92 & -0.24 \\
\hline Senegal & 0.69 & 0.87 & -0.17 \\
\hline Ethiopia & 0.69 & 0.86 & -0.17 \\
\hline C.A.R. & 0.63 & 0.85 & -0.22 \\
\hline Gambia & 0.60 & 0.85 & -0.25 \\
\hline Madagascar & 0.83 & 0.85 & -0.02 \\
\hline Rwanda & 0.67 & 0.78 & -0.11 \\
\hline Togo & 0.32 & 0.76 & -0.44 \\
\hline Malawi & 0.50 & 0.72 & -0.22 \\
\hline Uganda & 0.41 & 0.69 & -0.27 \\
\hline Zambia & 0.54 & 0.68 & -0.15 \\
\hline Congo, Dem. Republic & 0.37 & 0.64 & -0.28 \\
\hline Cameroon & 0.51 & 0.62 & -0.11 \\
\hline Nigeria & 0.41 & 0.57 & -0.16 \\
\hline Comoros & 0.40 & 0.54 & -0.14 \\
\hline Côte d'Ivoire & 0.58 & 0.50 & 0.09 \\
\hline Kenya & 0.48 & 0.48 & 0.00 \\
\hline Tanzania & 0.41 & 0.43 & -0.02 \\
\hline Ghana & 0.35 & 0.40 & -0.06 \\
\hline Congo, Brazzaville & 0.27 & 0.40 & -0.13 \\
\hline Gabon & 0.31 & 0.40 & -0.09 \\
\hline Zimbabwe & 0.30 & 0.35 & -0.06 \\
\hline Lesotho & 0.63 & 0.32 & 0.31 \\
\hline Namibia & 0.33 & 0.28 & 0.05 \\
\hline Swaziland & 0.28 & 0.20 & 0.08 \\
\hline South Africa & 0.22 & 0.16 & 0.06 \\
\hline
\end{tabular}

Note: Country indexes above 0.50 are highlighted.

Source: DHS, MICS-2 data 
Figure 1. Trends in completion of primary school, 33 African countries (population weighted)

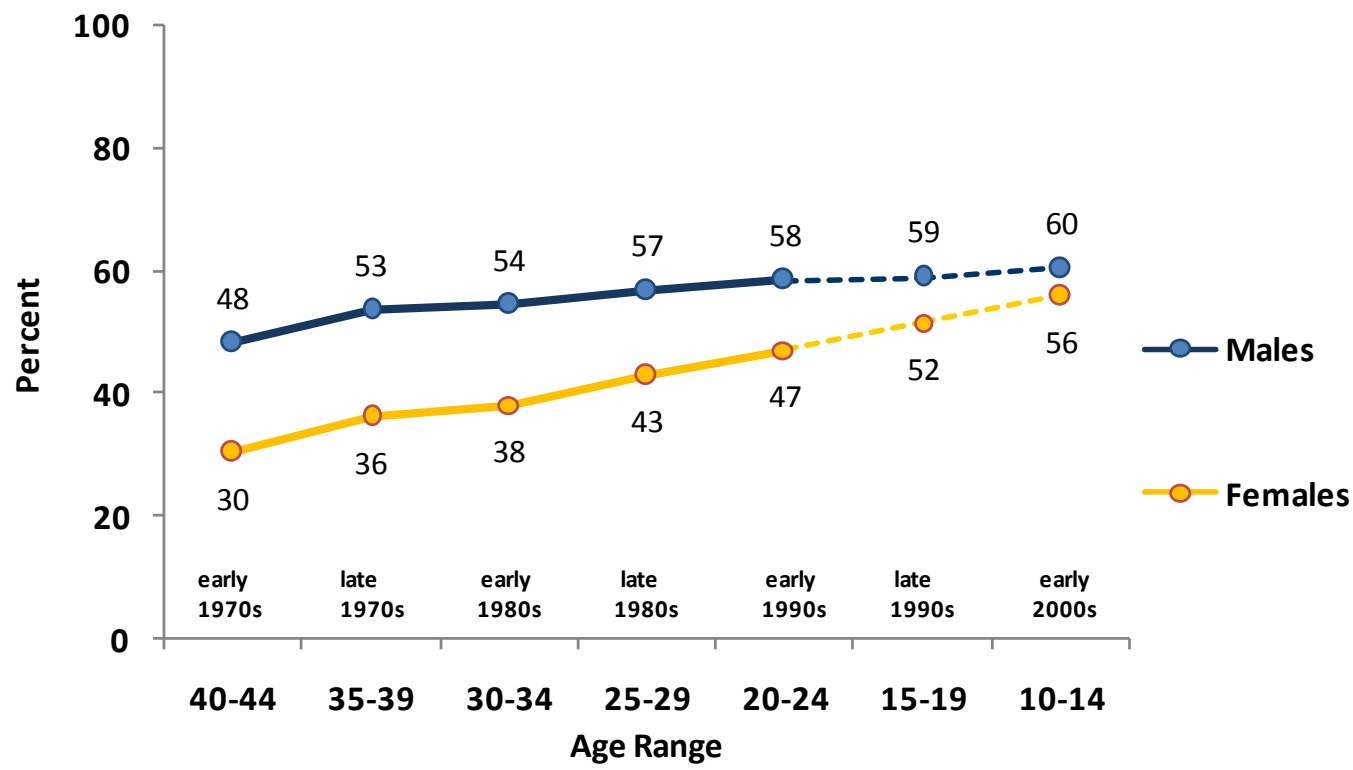

Source: DHS, MICS-2 data. 
Figure 2. Trends in primary school completion rates for those aged 20-24 and 40-44 (ranked from high to low for girls among 20-24-year-olds), by country and sex

\section{(a) Girls}

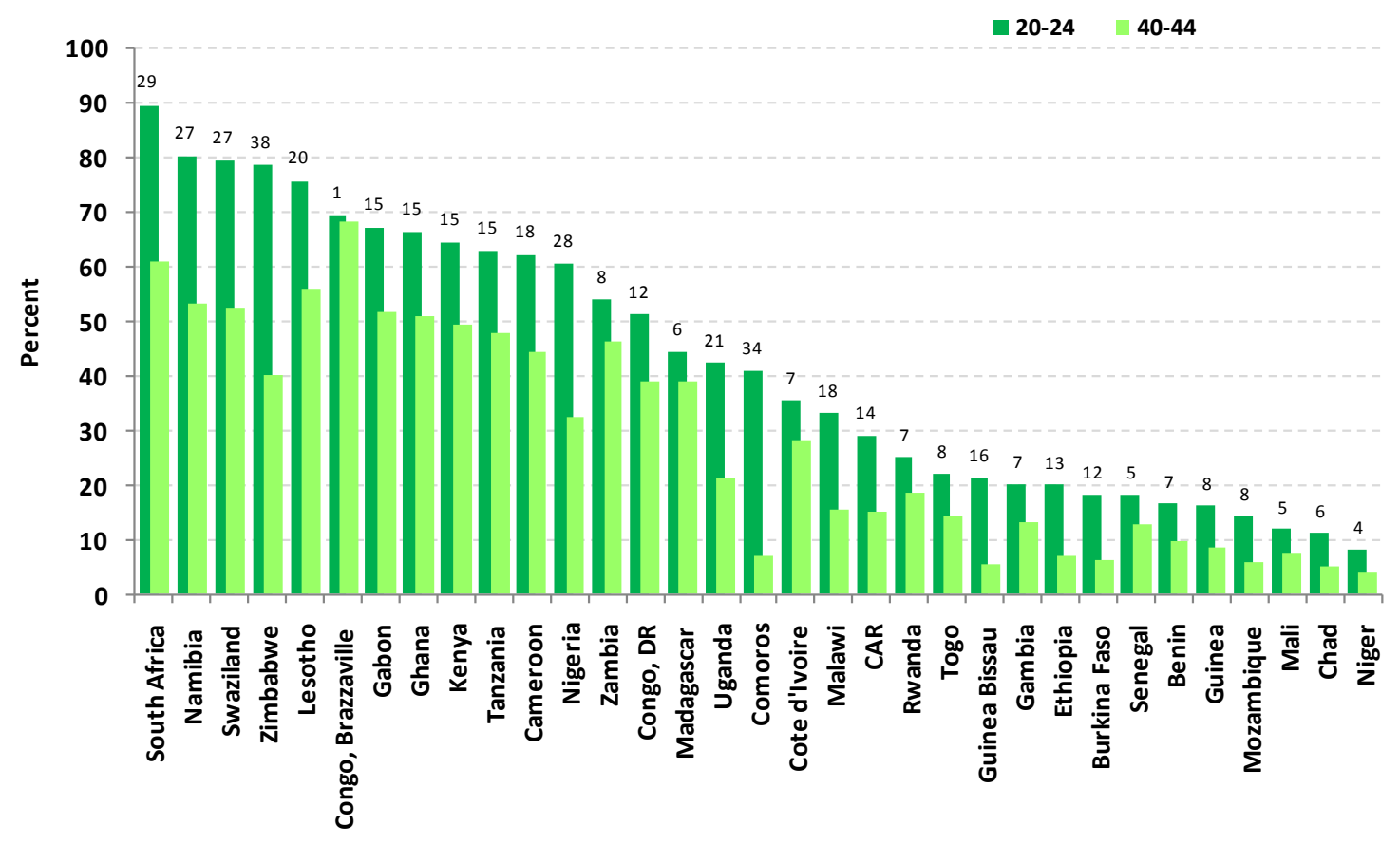

(b) Boys

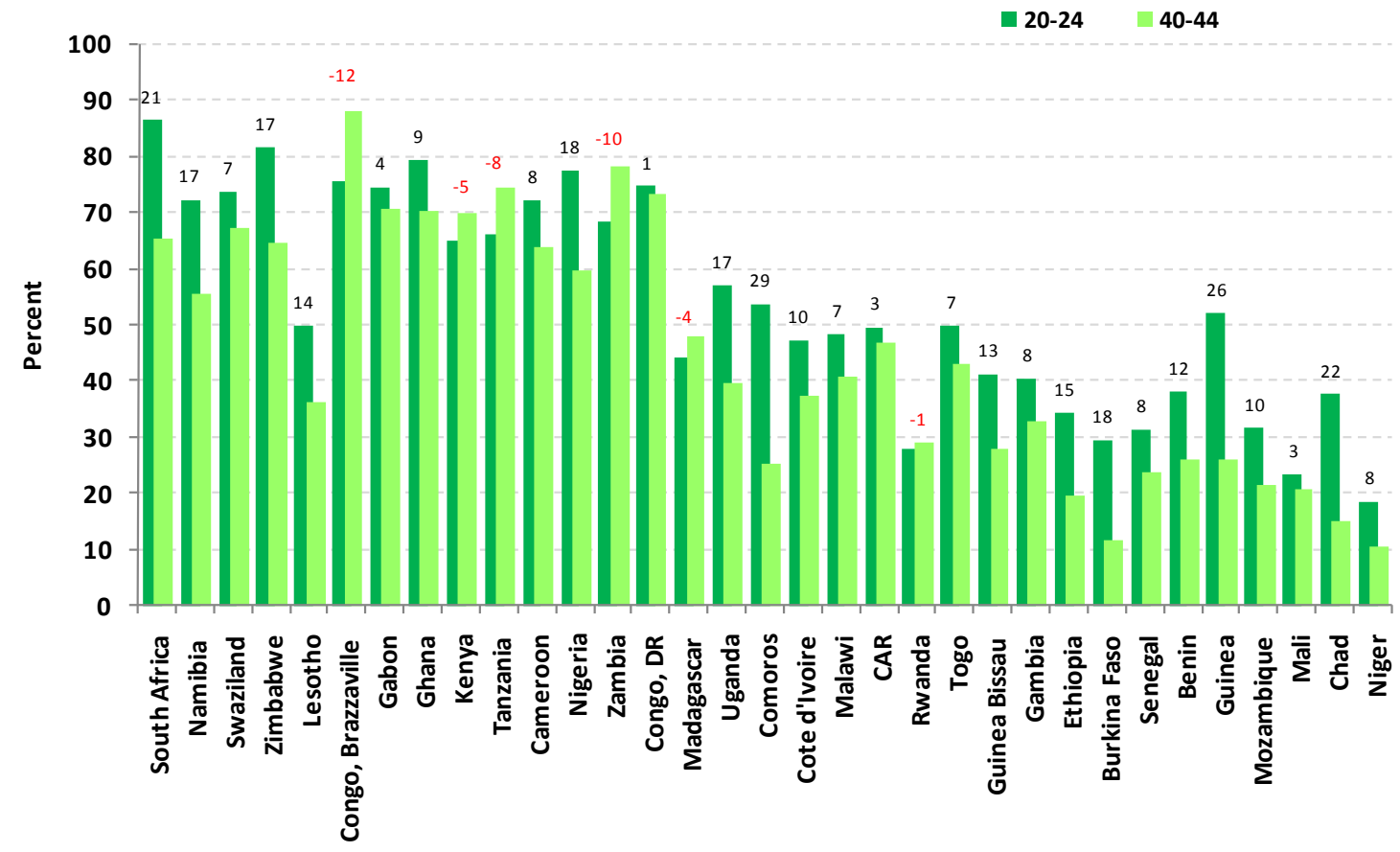

Note: Data label values represent absolute change between 40-44 and 20-24-year-olds; negative changes in red. Source: DHS, MICS-2 data. 
Figure 3. Variations in the relationship between primary school completion and PPP GNI per capita
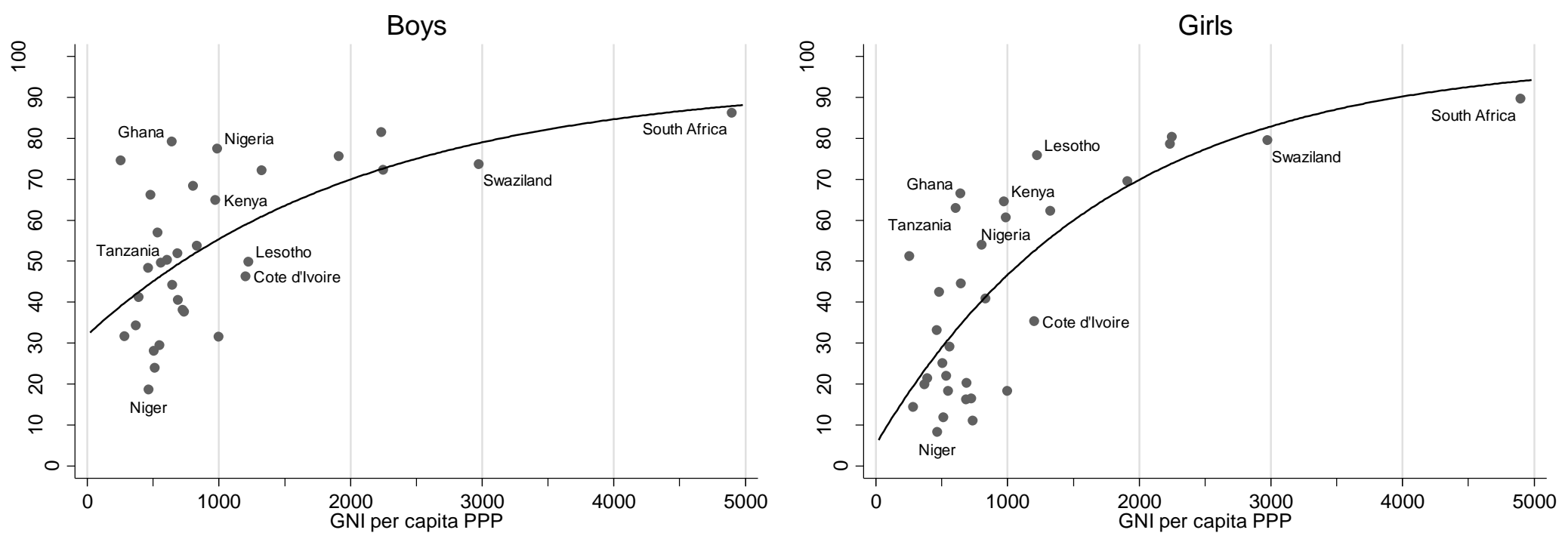

Source: DHS, MICS-2 data, World Bank (2008). 
Figure 4. Trends in the percentage point gender gap (boys minus girls) in primary school completion rates for those aged 20-24 and 40-44, by country (ranked from high to low completion rates of girls, 20-24, as in Figure 2)

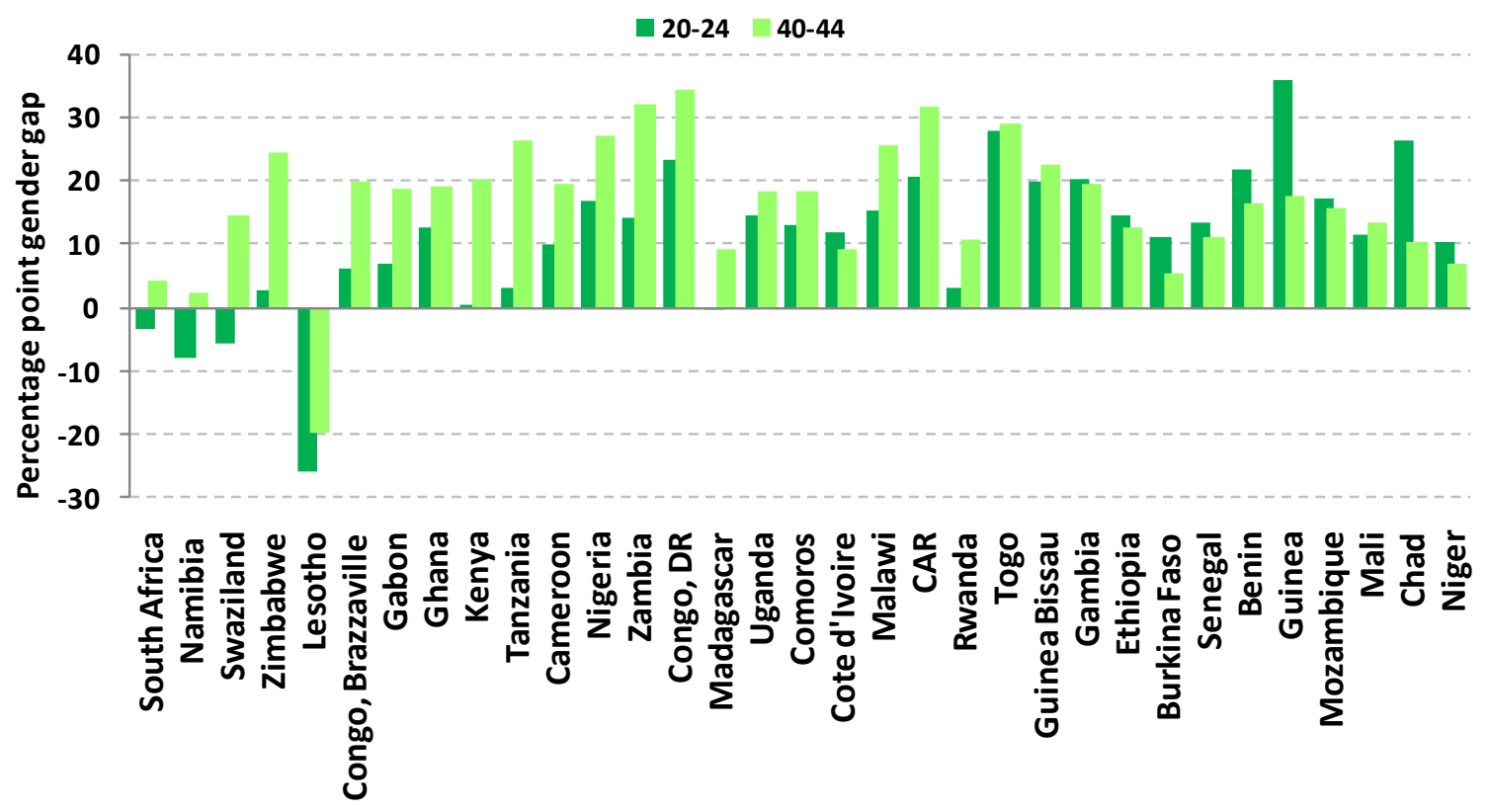

Source: DHS, MICS-2 data. 
Figure 5. Variations in the relationship between the gender gap in primary school completion among 20-24-year-olds and PPP GNI per capita

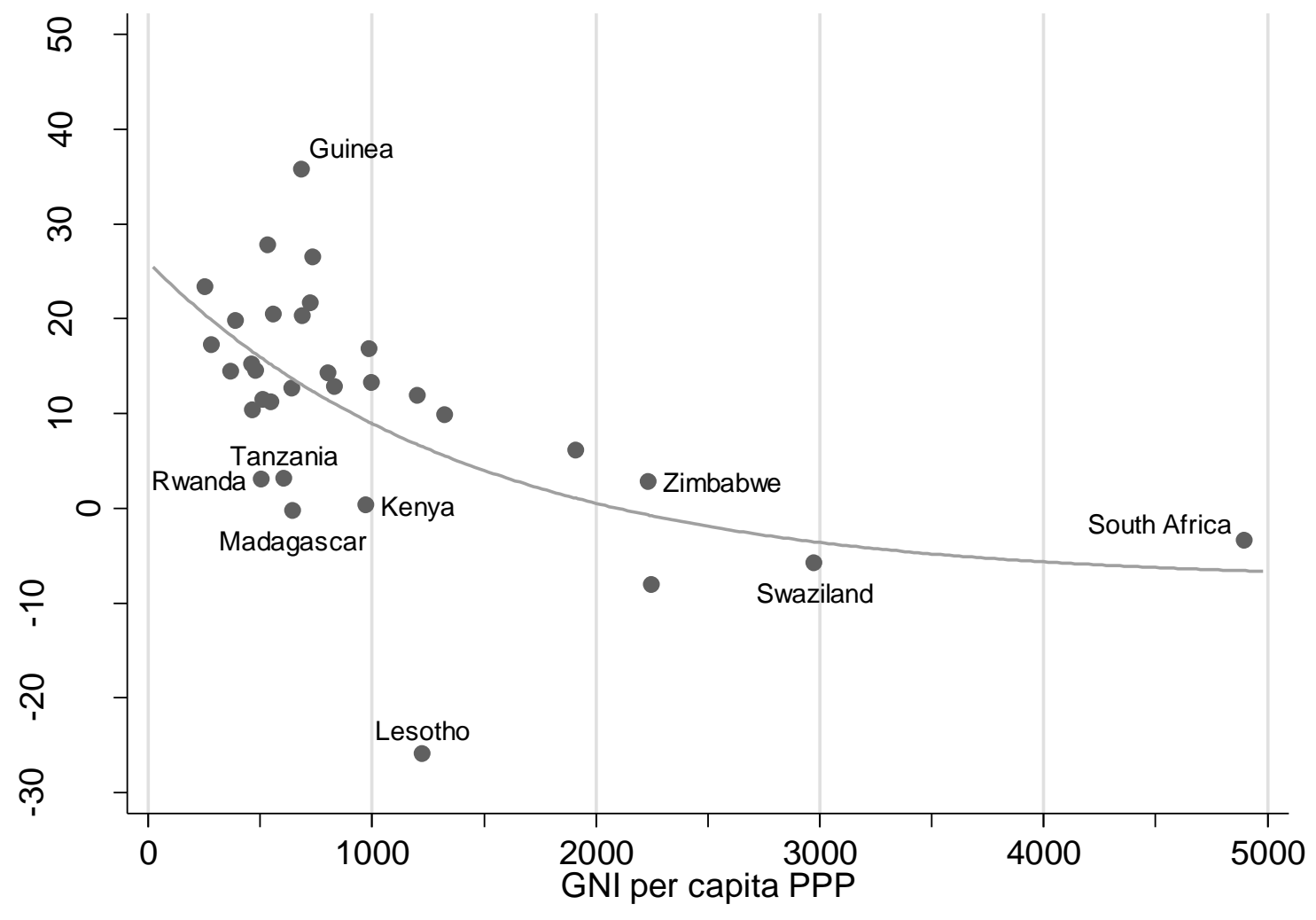

Source: DHS, MICS-2 data, World Bank (2008). 
Figure 6. Relationship between the percentages of women aged 20-24 who completed primary school and those who can read a simple sentence at grade 5, 24 countries

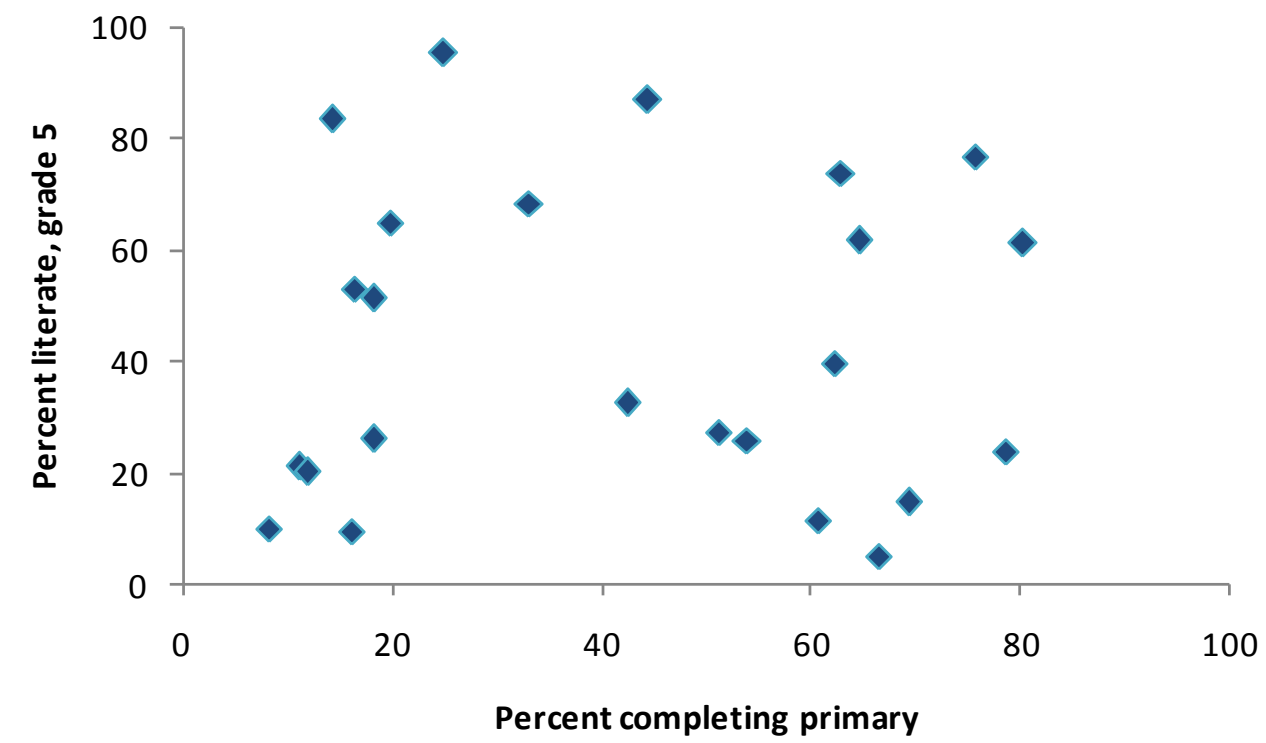

Source: DHS data. 
Figure 7. Relationship between the percentage of women aged 20-24 who can read a simple sentence at grade 5 and PPP GNI per capita

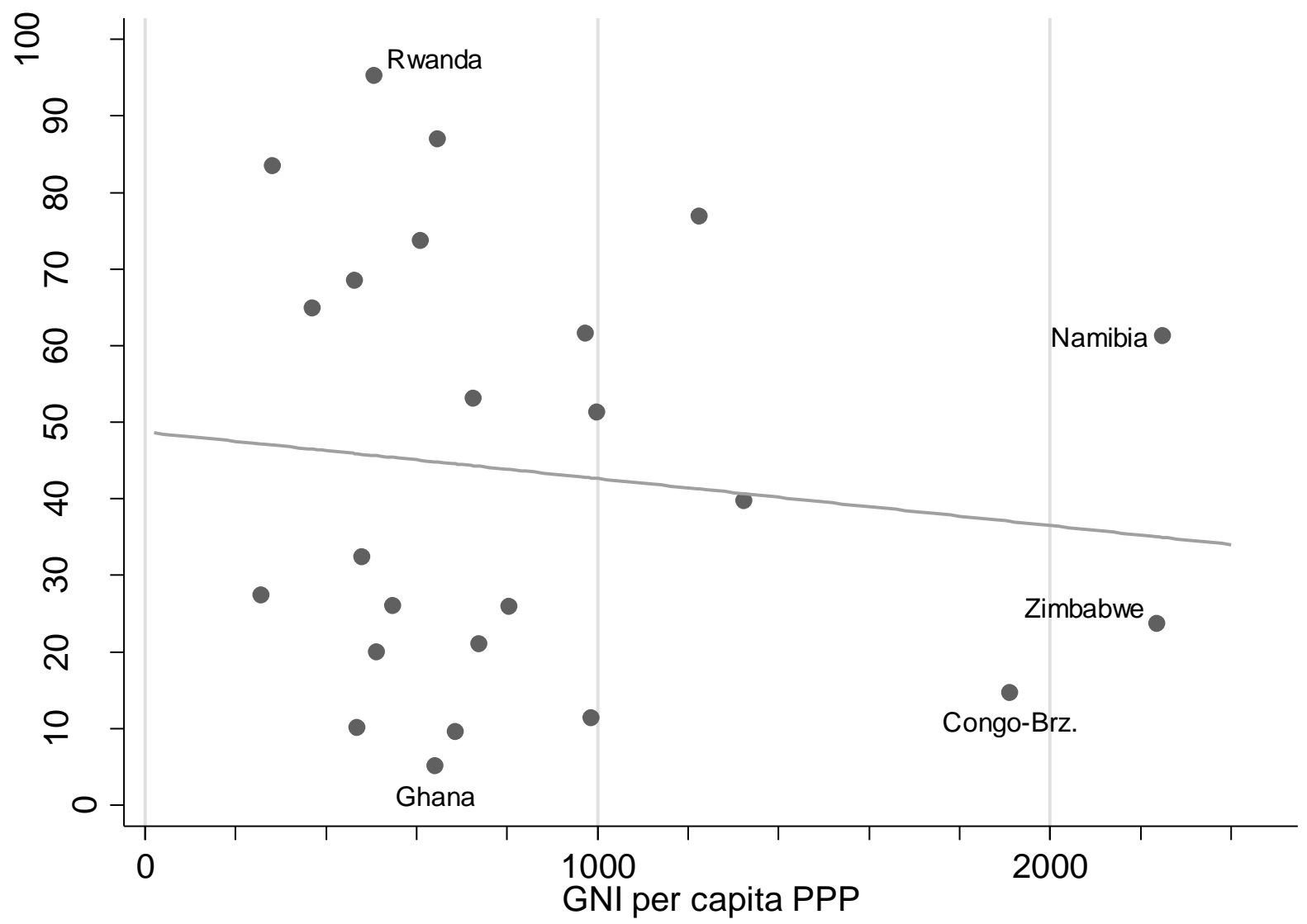

Source: DHS, MICS-2 data, World Bank (2008). 
Figure 8. Percentage of 20-24-year-olds completing primary school, by sex and socioeconomic status (both figures are ranked from low to high by girls who are "best off")

(a) Girls

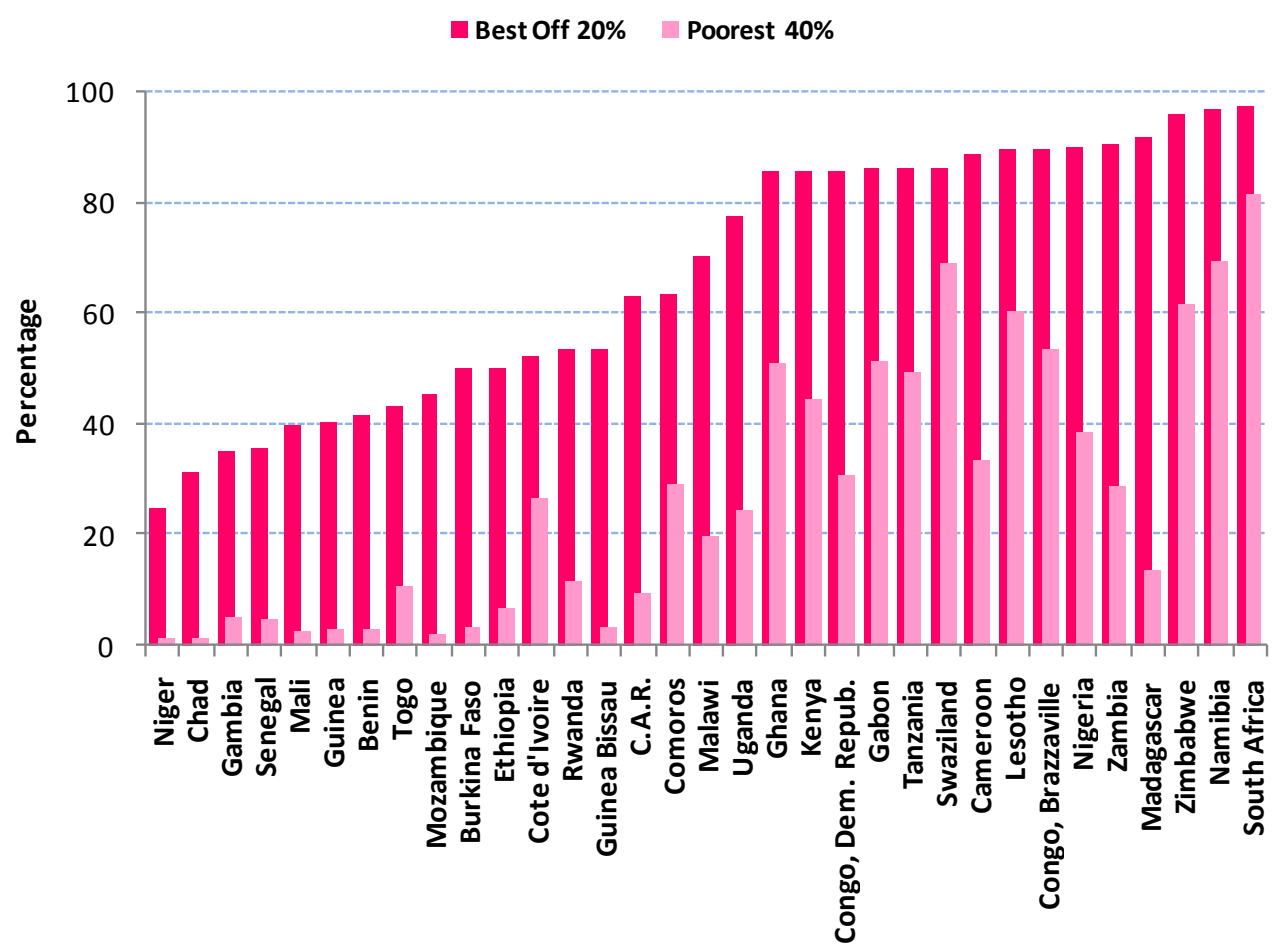

(b) Boys

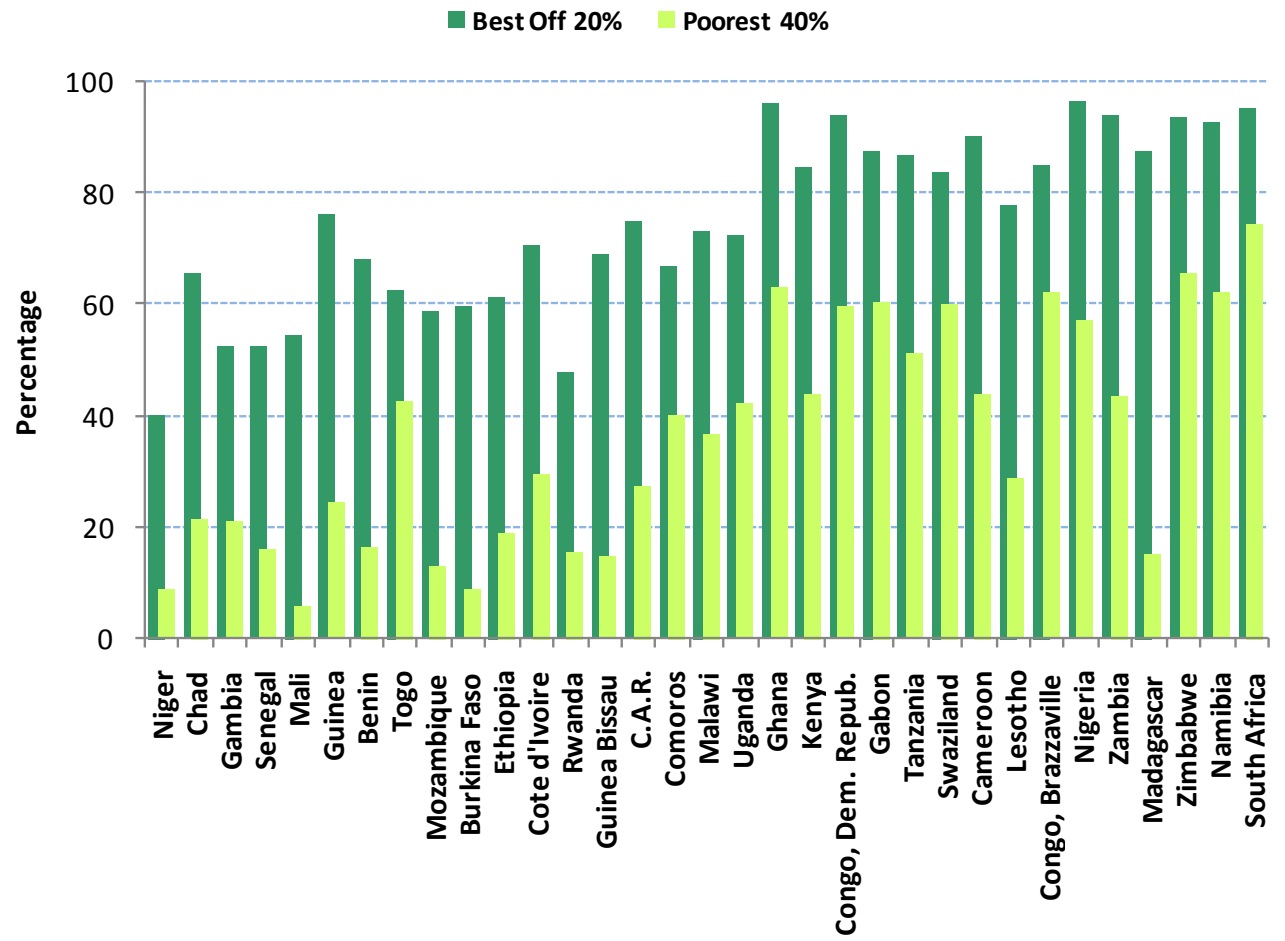

Source: DHS, MICS-2 data. 
Figure 9. Primary school completion of 20-24-year-olds relative to 40-44-year-olds, 24 African countries with PPP GNI below \$1000, by former colonial rulers

\section{(a) Girls}

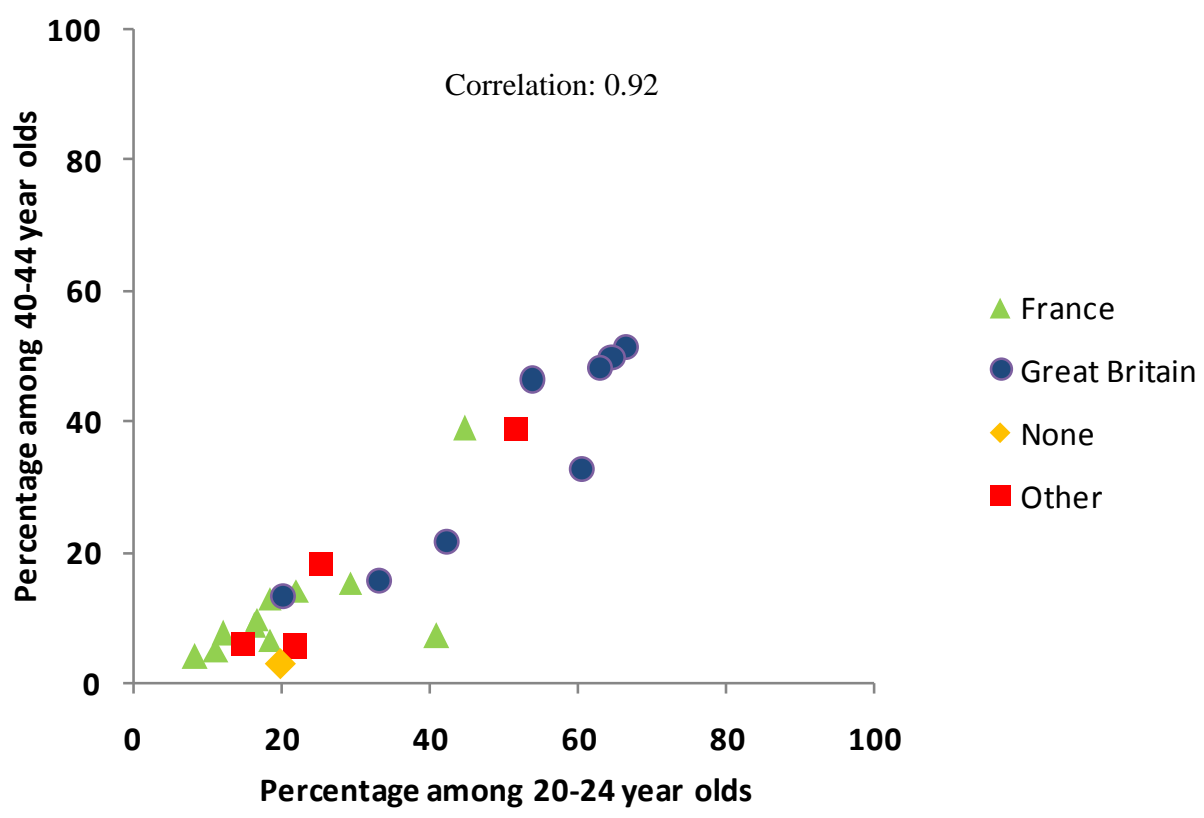

(b) Boys

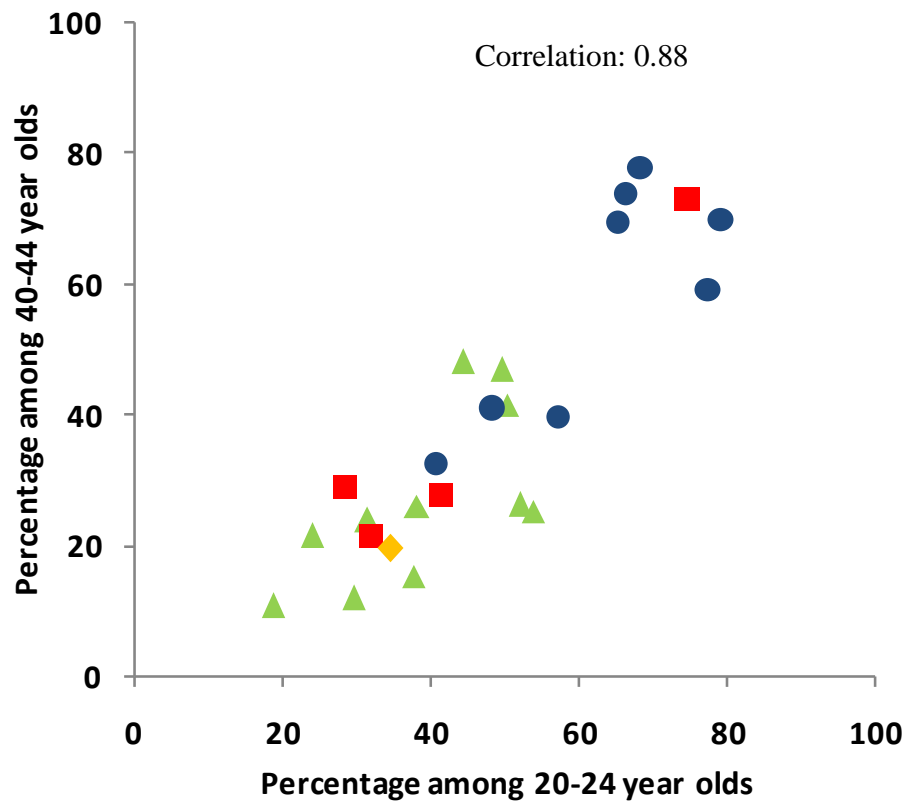

$\triangle$ France

- Great Britain

$\checkmark$ None

Other

Source: DHS, MICS-2 data, World Bank (2008). 
Figure 10. Percentage of young women aged 20-24 who can read a simple sentence, by grade attained, selected poor countries (primary school completion rates in parentheses)

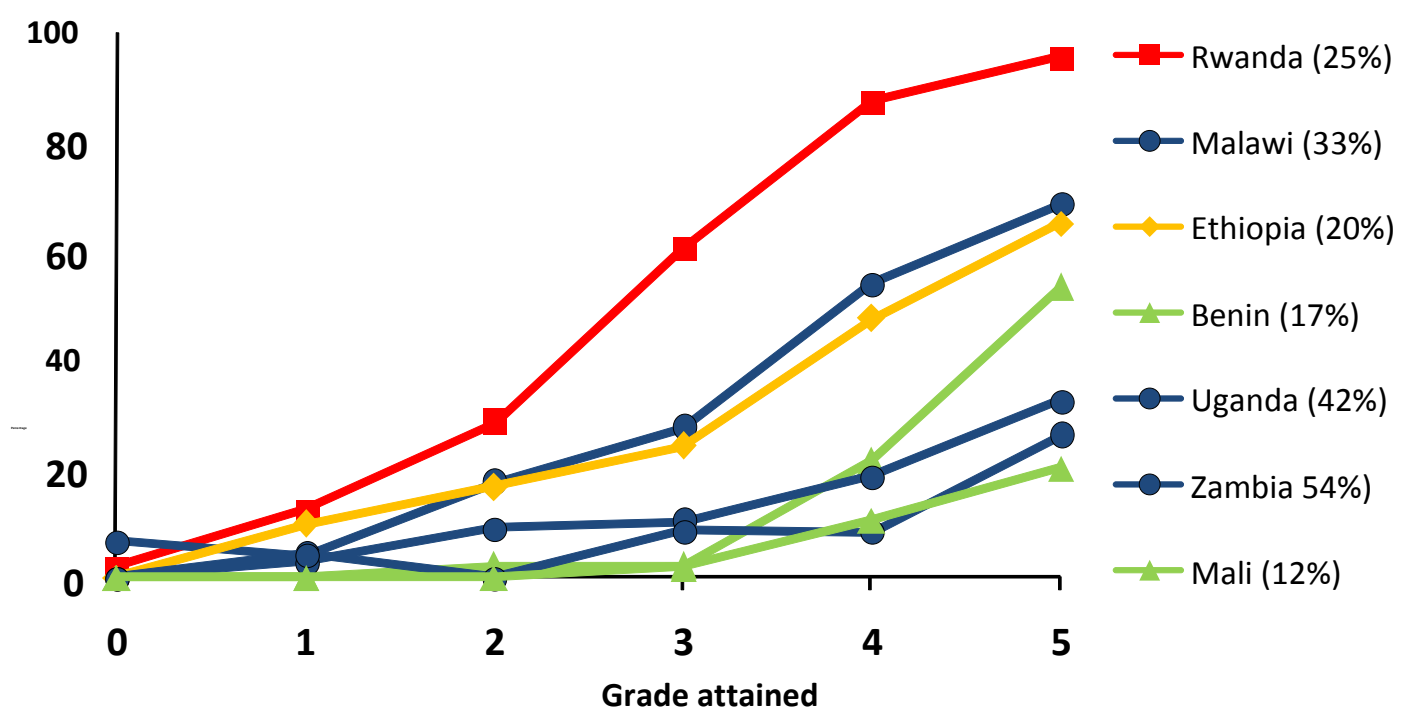

Source: DHS, MICS-2 data.

Note: Numbers in parentheses represent percentage completing primary school for each country.

\section{Colonial designations:}

$\Delta$ France

- Great Britain

* None

nother 
Appendix Table 1. Selected sub-Saharan African countries participating in Demographic and Health Surveys (DHS) or UNESCO Multiple Indicator Cluster Survey (MICS-2) from 1998-2007

\begin{tabular}{|c|c|c|c|c|c|}
\hline Country & $\begin{array}{c}\text { Most } \\
\text { recent } \\
\text { survey } \\
\text { year }\end{array}$ & $\begin{array}{l}\text { Type of } \\
\text { survey }\end{array}$ & $\begin{array}{c}\text { PPP gross } \\
\text { national } \\
\text { income (PPP- } \\
\text { GNI) } \\
\text { per capita }^{\text {a }}\end{array}$ & $\begin{array}{c}\text { Population } \\
\text { of 10-24- } \\
\text { year-olds } \\
\text { in } 2005 \\
(000)\end{array}$ & $\begin{array}{c}\text { Population } \\
\text { weight } \\
\text { applied for } \\
\text { calculations }\end{array}$ \\
\hline Benin & 2001 & DHS & 726 & 2,805 & 0.01 \\
\hline Burkina Faso & 2003 & DHS & 548 & 4,616 & 0.02 \\
\hline Cameroon & 2004 & DHS & 1324 & 5,975 & 0.03 \\
\hline C.A.R. & 2000 & MICS-2 & 560 & 1,387 & 0.01 \\
\hline Chad & 2004 & DHS & 738 & 3,252 & 0.01 \\
\hline Comoros & 2000 & MICS-2 & 832 & 263 & 0.00 \\
\hline Congo, Brazzaville & 2006 & DHS & 1912 & 1,172 & 0.01 \\
\hline Congo, Dem. & 2007 & DHS & 256 & 18,985 & 0.08 \\
\hline Côte d'Ivoire & 1998-99 & DHS & 1202 & 6,422 & 0.03 \\
\hline Ethiopia & 2005 & DHS & 370 & 25,965 & 0.12 \\
\hline Gabon & 2000 & DHS & 9090 & 420 & 0.00 \\
\hline Gambia & 1999-00 & MICS-2 & 690 & 487 & 0.00 \\
\hline Ghana & 2003 & DHS & 642 & 7,469 & 0.03 \\
\hline Guinea & 2005 & DHS & 686 & 2,874 & 0.01 \\
\hline Guinea Bissau & 2000 & MICS-2 & 390 & 499 & 0.00 \\
\hline Kenya & 2003 & DHS & 974 & 12,217 & 0.05 \\
\hline Lesotho & 2004 & DHS & 1226 & 723 & 0.00 \\
\hline Madagascar & $2003-4$ & DHS & 646 & 5,974 & 0.03 \\
\hline Malawi & 2004 & DHS & 464 & 4,354 & 0.02 \\
\hline Mali & 2001 & DHS & 513 & 3,903 & 0.02 \\
\hline Mozambique & 2003 & DHS & 282 & 6,564 & 0.03 \\
\hline Namibia & 2000 & DHS & 2250 & 720 & 0.00 \\
\hline Niger & 2006 & DHS & 468 & 3,987 & 0.02 \\
\hline Nigeria & 2003 & DHS & 986 & 46,777 & 0.21 \\
\hline Rwanda & 2005 & DHS & 506 & 3,488 & 0.02 \\
\hline Senegal & 2005 & DHS & 998 & 3,887 & 0.02 \\
\hline South Africa & 1998-00 & DHS & 4898 & 14,597 & 0.07 \\
\hline Swaziland & 1999-00 & MICS-2 & 2976 & 426 & 0.00 \\
\hline Tanzania & 2004 & DHS & 608 & 12,610 & 0.06 \\
\hline Togo & 1998 & DHS & 534 & 2,056 & 0.01 \\
\hline Uganda & 2006 & DHS & 480 & 9,825 & 0.04 \\
\hline Zambia & 2001-02 & DHS & 804 & 3,929 & 0.02 \\
\hline Zimbabwe & $2005-6$ & DHS & $2236^{\mathrm{b}}$ & 5,020 & 0.02 \\
\hline
\end{tabular}

Sources: DHS, MICS-2 data, United Nations 2005 population estimates (United Nations 2007), World Development Indicators (World Bank 2008).

${ }^{a}$ GNI PPP was averaged from data reported for the years ranging from 10-14 years before the most recent DHS/MICS-2 survey date.

${ }^{\mathrm{b}}$ Source for Zimbabwe, WDI (World Bank 2006) 


\section{Poverty, Gender, and Youth Working Papers}

If still in print, single copies of up to three working papers from 1989 through 2003 are available free of charge.

Beginning with the 2004 issues, working papers are no longer available in print format. Instead they are distributed electronically. As each new paper is completed, subscribers are notified by e-mail and a link to the paper is provided.

To subscribe to the Poverty, Gender, and Youth working paper e-mail notification list, or to obtain back issues from 1989 to 2003, please send your request to pgywp@ popcouncil.org.

PDFs of recent issues are available at www.popcouncil.org/publications/wp/index.html

2009

14 Cynthia B. Lloyd and Paul C. Hewett, "Educational inequalities in the midst of persistent poverty: Diversity across Africa in educational outcomes."

13 Wendy Baldwin and Judith Diers, "Demographic data for development in sub-Saharan Africa."

2008

12 Sajeda Amin and Lopita Huq, "Marriage considerations in sending girls to school in Bangladesh: Some qualitative evidence."

11 S. Chandrasekhar and Abhiroop Mukhopadhyay, "Multiple dimensions of urban well-being: Evidence from India"

10 Sajeda Amin and Luciana Suran, "Terms of marriage and time-use patterns of young wives: Evidence from rural Bangladesh."

9 John Bongaarts, Thomas Buettner, Gerhard Heilig, and François Pelletier, "Has the HIV epidemic peaked?"
8 Barbara S. Mensch, Paul C. Hewett, Richard Gregory, and Stephane Helleringer, "Sexual behavior and STI/HIV status among adolescents in rural Malawi: An evaluation of the effect of interview mode on reporting."

7 John Bongaarts, "Fertility transitions in developing countries: Progress or stagnation?"

2007

6 Cynthia B. Lloyd, "The role of schools in promoting sexual and reproductive health among adolescents in developing countries."

5 Ann Biddlecom, Richard Gregory, Cynthia B. Lloyd, and Barbara S. Mensch, "Premarital sex and schooling transitions in four subSaharan African countries."

4 Sajeda Amin, John B. Casterline, and Laura Spess, "Poverty and fertility: Evidence and agenda."

3 Bussarawan Teerawichitchainan and James F. Phillips, "Ethnic differentials in parental health seeking for childhood illness in Vietnam." 
2 Zachary Zimmer, Kim Korinek, John Knodel, and Napaporn Chayovan, "Support by migrants to their elderly parents in rural Cambodia and Thailand: A comparative study."

1 Sharon Ghuman and Cynthia B. Lloyd, "Teacher absence as a factor in gender inequalities in access to primary schooling in rural Pakistan." 